\title{
Cutaneous Melanoma pNO TNM Finding v6 and v7
}

National Cancer Institute

\section{Source}

National Cancer Institute. Cutaneous Melanoma pNO TNM Finding v6 and v7. NCI

Thesaurus. Code C48855.

Cutaneous melanoma without involvement of regional lymph nodes. (from AJCC 6th and 7th Eds.) 